\title{
Re: Five Things I Wish I Would Have Known Earlier in My Career: Lessons Learned in Peyronie's Disease Surgery
}

Lue TF, Shindel AW

University of California-San Francisco Faculty of Medicine, Department of Urology, San Francisco, CA, USA

J Sex Med 2018;15:1070-1072. doi: 10.1016/j.jsxm.2018.04.645. Epub 2018 May 31.

\section{EDITORIAL COMMENT}

In this invited commentary, World's famous expert in Peyronie's disease (PD) surgery, Tom Lue et al. shared their decades of experiences on use of saphenous vein for plaque incision and grafting, management of large calcified or ossified plaques, circumcising vs longitudinal incisions, management of hourglass deformity and circumferential narrowing, and management of residual curvature after penile prosthesis implantation. The authors suggest no treatment in patients for whom penile deformity poses no or minimal bother. They stated that surgery was indicated for large ossified plaques, severe hourglass deformities or indentations with marked hinging, curvatures greater than $90^{\circ}$, and failure of collagenase. They recommended collagenase injections as a safe and effective first-line therapy for bothersome PD.

Emre Bakırcıŏlu, MD

${ }^{\circ}$ Copyright 2019 by the Association of Urological Surgery / Journal of Urological Surgery published by Galenos Publishing House. 